\title{
Spinal Adverse Events Severity System, version 2 (SAVES-V2): inter- and intraobserver reliability assessment
}

\author{
Y. Raja Rampersaud, MD, ${ }^{1}$ Paul A. Anderson, MD, ${ }^{2}$ John R. Dimar II, MD, ${ }^{3}$ and \\ Charles G. Fisher, MD, ${ }^{4}$ on behalf of the Spine Trauma Study Group and Degenerative Spine \\ Study Group
}

\begin{abstract}
'Division of Orthopedic Surgery, Department of Surgery, University of Toronto, ON, Canada; ${ }^{2}$ Department of Orthopedics \& Rehabilitation, University of Wisconsin Hospitals, Madison, Wisconsin; ${ }^{3}$ Department of Orthopaedic Surgery, University of Louisville School of Medicine, Louisville, Kentucky; and ${ }^{4}$ Department of Orthopedics, Division of Spine, University of British Columbia, Vancouver, British Columbia, Canada
\end{abstract}

OBJECTIVE Reporting of adverse events (AEs) in spinal surgery uses inconsistent definitions and severity grading, making it difficult to compare results between studies. The Spinal Adverse Events Severity System, version 2 (SAVESV2) aims to standardize the classification of spine surgery AEs; however, its inter- and intraobserver reliability are unknown. The objective of this study was to assess inter- and intraobserver reliability of the SAVES-V2 grading system for assessing AEs in spinal surgery.

METHODS Two multinational, multicenter surgical study groups assessed surgical case vignettes (10 trauma and 12 degenerative cases) for AE occurrence by using SAVES-V2. Thirty-four members of the Spine Trauma Study Group (STSG) and 17 members of the Degenerative Spine Study Group (DSSG) participated in the first round of case vignettes. Six months later, the same case vignettes were randomly reorganized and presented in an otherwise identical manner. Inter- and intraobserver agreement on the presence, severity, number, and type of $A E$, as well as the impact of the AE on length of stay (LOS) were assessed using intraclass correlation (ICC), Cohen's kappa value, and the percentage of participants in agreement.

RESULTS Agreement on the presence of AEs ranged from $97 \%$ to $100 \%$ in the 2 groups. Severity classification showed substantial interobserver (ICC $=0.75$ for both groups) and intraobserver (ICC $=0.70$ in DSSG, 0.71 in STSG) agreement. Judgments on the number of AEs showed high interobserver agreement and moderate intraobserver agreement in both groups. Both the STSG and DSSG had high intraobserver agreement on the type of AE; interobserver agreement for $A E$ type was high in the STSG and fair in the DSSG. Agreement on impact of the AE on LOS was excellent in the DSSG and fair in the STSG.

CONCLUSIONS There was good agreement on the presence, severity, and number of AEs in both trauma and degenerative cases in using the SAVES-V2. This grading system is a simple, reliable tool for identifying and capturing AEs in spinal surgery.

http://thejns.org/doi/abs/10.3171/2016.1.SPINE14808

KEY WORDS reliability; interobserver; intraobserver; adverse event; complication; surgery

$\mathrm{T}$

THE Institute of Medicine reports on patient safety have raised numerous concerns from the public, health care providers, and other stakeholders regarding patient safety. ${ }^{12,13}$ At a basic level, a standard language and consistent definitions for what constitutes an adverse event (AE) have been lacking. ${ }^{3,5,9,11,15}$ Current terminology, such as "complication," "AE," "adverse occurrence," or "near misses," can have different meanings but are often used interchangeably. Furthermore, most AE studies use undefined terms, such as "major" or "minor" events, and

ABBREVIATIONS AE = adverse event; DS = degenerative spondylolisthesis; DSSG = Degenerative Spine Study Group; ICC = intraclass correlation; JCAHO = Joint Commission on Accreditation of Healthcare Organizations; LOS = length of stay; LS = lumbar stenosis; SAVES-V2 = Spinal Adverse Events Severity System, version 2; STSG = Spine Trauma Study Group.

SUBMITTED September 16, 2014. ACCEPTED January 20, 2016.

INCLUDE WHEN CITING Published online April 8, 2016; DOI: 10.3171/2016.1.SPINE14808. 
are typically procedure or disease specific. In addition, malpractice, professional, and financial implications of AEs can result in their underreporting. 1,15,24,27,28,42

Despite significant efforts by international organizations and policy makers, a common language for medical error is still not globally used..$^{2,5,9,15,17,29}$ A comprehensive patient safety event taxonomy was developed and published in 2005 by the Joint Commission on Accreditation of Healthcare Organizations (JCAHO). ${ }^{5,14,40}$ Although the report was appropriately reflective regarding the scope and depth of patient safety assessment, the complexity of this system requires a potentially prohibitive amount of resources and commitment from all levels of health care in order to be universally implemented. These challenges are reflected by the "medical error" literature, which is predominantly disease, procedure, or process specific rather than comprehensive as proposed by the JCAHO. ${ }^{5}$

Spinal surgery is typically perceived as high risk; however, the reported AE rate associated with spinal surgery has significant variability. ${ }^{19,21,32,34,38,41}$ Although diagnosis, patient factors, and surgical magnitude play a role, the reported incidence of AEs will also be affected by the working definition of-and what constitutes-an AE and the nature in which it is captured (i.e., prospectively vs retrospectively). ${ }^{20,26,34,39}$ Consequently, quantitative comparisons of studies reporting or pooling AE data are typically not feasible. Furthermore, most large-scale studies utilizing administrative databases, although valuable, tend to underestimate the incidence and type of AEs and lack the clinical granularity required to apply findings to a specific patient or subgroup., ${ }^{7,32}$

To address the above issues, a comprehensive, clinically relevant, yet simple classification system has been developed in the hopes of providing a universal evaluation of spinal AEs. The primary objective of the present study was to evaluate the inter- and intraobserver reliability of a classification system (Spinal Adverse Events Severity System, version 2 [SAVES-V2]) for the clinical severity grading of AEs associated with spinal surgery. We believe the SAVES-V2 adequately characterizes clinically important AEs associated with surgical spinal care.

\section{Methods \\ Study Design and Setting}

Multicenter, multidisciplinary (neurosurgery and orthopedic surgery) inter- and intraobserver reliability assessment using case vignettes was performed at consecutive meetings of the former Spine Trauma Study Group (STSG) and the Degenerative Spine Study Group (DSSG).

\section{Development of the AE Grading System}

For more consistent $\mathrm{AE}$ categorization and severity grading within the STSG and DSSG databases, a bestavailable evidence and consensus expert opinion methodology was used to develop SAVES-V2. This system was developed by a nucleus group (Y.R.R., P.A.A., J.R.D., C.G.F.) followed by an iterative consensus-modified Delphi process within the membership of the STSG and DSSG.

Based on the available literature and the use of multiple sources of AE capture from surgical societies (e.g., Scoliosis Research Society, North American Spine Society), an $\mathrm{AE}$ was defined as any event due to medical or surgical management (but not resulting from underlying disease process or injury) that leads to patient harm or requires additional monitoring or treatment. $2,13,17,20,25,26,36,37,40$

Decisions on the development of the severity grading scheme were heavily weighted toward ease of use and demonstrated reliability of any existing AE categorization system. Furthermore, given our working definition of $\mathrm{AE}$ (i.e., physical harm has come to the patient), subcomponents of systems in which "near misses" or the "potential for harm" were categorized, such as those by Mirza et al. ${ }^{20}$ or Chang et al., ${ }^{5}$ were not considered. With these matters taken into account, the 4-category SAVES system, which was proposed and validated for interobserver reliability by Rampersaud et al., ${ }^{26}$ was modified to a 6-category AE severity classification system (SAVES-V2). The working definitions of the existing and new categories were modified by the nucleus group and by consensus were approved by the larger STSG and DSSG groups (severity grades are presented in Table 1). The Grade 5 severity class was specifically added to capture significant neurological deterioration, life- or limb-threatening AEs, or events that may be less clinically severe but have been designated by the practitioner's institution or health system as mandatory reportable events. Our rationale was that this would enable easier identification of the more clinical catastrophic events or AEs that have resulted from institutional process failures.

\section{Reliability Assessment}

Twenty-two subspecialized surgical case vignettes (see online-only Appendices 1 and 2 for written summaries of each case) with representative single or multiple AEs within the same patient were presented to study participants at the 2009-2010 meetings of the STSG (10 trauma cases) and DSSG (12 degenerative cases). The SAVES-V2 $\mathrm{AE}$ and severity grade definitions (Tables $1-3$ ) were provided to the participant groups, as was a short period of time for clarification as required. A similar process was conducted for each case. 1) After the case and pertinent images were presented, participants were able to ask questions on the clinical facts of the case. To enable SAVES-V2 assessment in a pragmatic fashion, any question regarding an AE occurrence, definitions of AE severity grades, or other system questions were deferred to the SAVES-V2 form (described in Tables 1-3 and previously published in Street et al. ${ }^{34}$ ) Furthermore, no operational definitions for specific AEs or postdischarge information on short- or long-term outcome of the case were provided. 2) Participants were given the definition of an $\mathrm{AE}$ and the following tip: in patients with stable preexisting comorbidities, an acute exacerbation related to that condition but not responsive to the patient's routine medication(s) is considered an $\mathrm{AE}$ (e.g., controlled, stable coronary artery disease with good preoperative exercise tolerance followed by postoperative acute myocardial infarction). 3) The participants were then asked to independently indicate whether an $\mathrm{AE}$ had occurred in the case and 4) to independently identify the specific AE from the provided list (Tables 2 and 3). 
TABLE 1. SAVES-V2 severity grades

\begin{tabular}{cc}
$\begin{array}{c}\text { Severity } \\
\text { of AE }\end{array}$ & \multicolumn{1}{c}{ Clinical Impact } \\
\hline 1 & AE does not require treatment \& has no adverse effect \\
\hline 2 & $\begin{array}{c}\text { AE requires minor invasive (e.g., Foley catheter, nasogastric } \\
\text { tube) or simple treatment but has no long-term effect }\end{array}$ \\
\hline 3 & $\begin{array}{c}\text { AE requires invasive (e.g., surgery) or complex treatment } \\
\text { (e.g., monitored bed) \& is most likely to have a temporary } \\
\text { (<6 mos) adverse effect on outcome }\end{array}$ \\
& $\begin{array}{c}\text { AE requires invasive (e.g., surgery) or complex treatment } \\
\text { (e.g., monitored bed) \& is most likely to have a prolonged } \\
\text { (>6 mos) adverse effect on outcome* }\end{array}$ \\
& $\begin{array}{c}\text { Significant neural injury (i.e., } 1 \text { or more grade deterioration } \\
\text { in ASIA grade) or serious life- or limb-threatening event } \\
\text { or any sentinel event } \dagger\end{array}$ \\
\hline 6 & AE resulting in death \\
\hline
\end{tabular}

ASIA = American Spinal Injury Association.

* Any AE with a functionally significant (i.e., patient reported) and most likely prolonged (> 6 months) adverse effect on outcome, regardless of required treatment (e.g., nerve root injury that cannot be treated), should be Grade 4 . $\dagger$ A sentinel event is an unexpected, serious life- or limb-threatening event(s) or any event (e.g., wrong level surgery) that necessitates a formal institutional review process and reporting as defined by your specific institution.

The SAVES-V2 form contains 14 specific intraoperative (e.g., dural lesion) and 22 specific postoperative AEs (e.g., myocardial infarction) plus an "other" category to enable free text for naming an $\mathrm{AE}$ that is not identified on the list. More than 1 AE could be identified. 5) Participants then graded the severity of the AE(s) using the SAVESV2 definitions provided (Table 1). No mortality cases (i.e., Grade 6 AEs) were included. 6) Finally, the participants were asked to estimate the effect of the $\mathrm{AE}$ on hospital length of stay (LOS) based on the general LOS for the type of procedure in the specific patient presented. Six responses were possible: none, 1-2 days, 3-7 days, 8-14 days, 15-28 days, and more than 28 days. The following

\section{TABLE 2. SAVES-V2 intraoperative AE categories}

\begin{tabular}{l}
\hline \multicolumn{1}{c}{ Intraop AE Category } \\
\hline 1. Allergic reaction \\
\hline 2. Anesthesia related \\
\hline 3. Bone implant interface failure requiring revision \\
\hline 4. Cardiac \\
\hline 5. Cord injury \\
\hline 6. Dural tear \\
\hline 7. Hardware malposition requiring revision \\
\hline 8. Hypotension (systemic $<85 \mathrm{~mm} \mathrm{Hg}$ for $15 \mathrm{~min})$ \\
\hline 9. Massive blood loss $(>5 \mathrm{~L}$ in $24 \mathrm{hrs}$ or $>2 \mathrm{~L} \mathrm{in} 3 \mathrm{hrs})$ \\
\hline 10. Nerve root injury \\
\hline 11. Pressure sores \\
\hline 12. Vascular injury \\
\hline 13. Airway/ventilation \\
\hline 14. Visceral injury \\
\hline 15. Other (specify:
\end{tabular}

\section{TABLE 3. SAVES-V2 postoperative AE categories}

\begin{tabular}{|c|c|}
\hline \multicolumn{2}{|c|}{ Postop AE Category } \\
\hline \multicolumn{2}{|c|}{ 1. Cardiac arrest/failure/arrhythmia } \\
\hline \multicolumn{2}{|c|}{ 2. Construct failure with loss of correction } \\
\hline \multicolumn{2}{|c|}{ 3. Construct failure without loss of correction } \\
\hline \multicolumn{2}{|c|}{ 4. CSF leak/meningocele } \\
\hline \multicolumn{2}{|c|}{ 5. Deep vein thrombosis } \\
\hline \multicolumn{2}{|c|}{ 6. Deep wound infection } \\
\hline \multicolumn{2}{|c|}{ 7. Delirium } \\
\hline \multicolumn{2}{|l|}{ 8. Dysphagia } \\
\hline \multicolumn{2}{|l|}{ 9. Dysphonia } \\
\hline \multicolumn{2}{|c|}{ 10. Gastrointestinal bleeding } \\
\hline \multicolumn{2}{|c|}{ 11. Hematoma } \\
\hline \multicolumn{2}{|c|}{ 12. Myocardial infarction } \\
\hline \multicolumn{2}{|c|}{ 13. Neurologic deterioration $\geq 1$ motor grade in ASIA motor scale } \\
\hline \multicolumn{2}{|c|}{ 14. Nonunion } \\
\hline \multicolumn{2}{|l|}{ 15. Pneumonia } \\
\hline \multicolumn{2}{|c|}{ 16. Postop neuropathic pain } \\
\hline \multicolumn{2}{|c|}{ 17. Pressure sores } \\
\hline \multicolumn{2}{|c|}{ 18. Pulmonary embolism } \\
\hline \multicolumn{2}{|c|}{ 19. Superficial wound infection } \\
\hline \multicolumn{2}{|c|}{ 20. Systemic infection } \\
\hline \multicolumn{2}{|c|}{ 21. Urinary tract infection } \\
\hline \multicolumn{2}{|c|}{ 22. Wound dehiscence } \\
\hline 23. Other (specify: & ) \\
\hline $\begin{array}{l}\text { Estimated effect of } A E \\
\square \text { None } \\
\square 1-2 \text { days } \\
\square 3-7 \text { days }\end{array}$ & $\begin{array}{l}\square \text { 8-14 days } \\
\square \text { 15-28 days } \\
\square \text { More than } 28 \text { days }\end{array}$ \\
\hline
\end{tabular}

instruction was provided: if multiple AEs occur simultaneously or in proximity, then report the most significant or cumulative effect if temporally distinct events occur. For AEs that require readmission for management, the effect of the AE on LOS should be reported as the entire LOS of the readmission.

Participants of round 1 were asked to complete the same process 6 months later. For round 2, the cases were randomly reorganized and presented in an otherwise identical manner as in round 1.

\section{Analysis}

Inter- and intraobserver reliability assessments were performed using intraclass correlation (ICC) and Cohen's kappa value to determine agreement on 4 aspects: occurrence of an $\mathrm{AE}$, specific type of $\mathrm{AE}$, severity of the $\mathrm{AE}$, and estimated impact of the AE on LOS. The primary analysis was based on inter- and intraobserver reliability of severity grading of AEs. Following the guidelines outlined by Landis and Koch, ${ }^{16}$ the strength of agreement measured by these statistics was interpreted as follows: $\leq 0=$ poor agreement, $0-0.2=$ slight agreement, $0.2-0.4=$ fair agreement, $0.4-0.6=$ moderate agreement, $0.6-0.8=$ substantial agreement, $0.8-1.0=$ near perfect agreement. Analysis was independently performed by $\mathrm{PhDx}$ Systems Inc. 


\section{Results}

Seventeen of the 20 available DSSG members and 34 of the 40 STSG members participated in round 1. Eight (47\%) of the initial 17 DSSG members who participated in round 1 were present at the next meeting and participated in round 2 . Twenty-eight $(82 \%)$ of the initial 34 STSG members who participated in round 1 were present for round 2 and completed the study. The inter- and intraobserver reliability scores for the DSSG and STSG are presented in Tables 4 and 5, respectively.

\section{Presence of AEs}

Overall, there was very high agreement (97\%-100\%) regarding the presence of an AE per our working definition (Tables 4 and 5). The interobserver reliability for the number of AEs was substantial in both study groups (ICC: DSSG $=0.71$, STSG $=0.70$ ); intraobserver reliability was moderate in both groups (ICC: DSSG $=0.49$, STSG $=$ $0.56)$.

\section{Types of AEs}

For the degenerative cases presented to the DSSG, the interobserver reliability was fair (Cohen's kappa $=0.38$; Table 4) for agreement on the specific type of AE; however, the intraobserver reliability was substantial (Cohen's kappa $=0.70$ ). For the STSG cases, near perfect interobserver $($ Cohen's kappa $=0.80)$ and substantial intraobserver $($ kappa $=0.65)$ reliability were demonstrated for the specific type of AE (Table 5). Similar results were found for both groups when only assessing cases with multiple AEs (inter- and intraobserver kappa values were 0.34 and 0.73 , respectively, for the DSSG and 0.69 and 0.71 , respectively, for the STSG). We determined that for the STSG participants, the $12 \%$ of responses (for specific type of AE) that were analyzed as incorrect were, in fact, clinically correct but categorized under a similar category. For example, a postoperative myocardial infarction has a specific category on the SAVES-V2 form; however, in some instances, the response was marked as cardiac rather than myocardial infarction. In other instances, the term "other" was marked along with a written response when a specific category was available. To maintain a worst-case scenario, the analysis was not corrected for these occurrences. For the DSSG, $18 \%$ of responses were subject to similar errors.

\section{Severity of AEs}

The overall inter- and intraobserver reliability was sub- stantial for grading AE severity (Grades $1-5$ ) for both the DSSG (ICC $=0.75$ and 0.70, respectively; Table 4) and STSG $($ ICC $=0.75$ and 0.71 , respectively; Table 5).

\section{Impact on LOS}

The inter- and intraobserver reliability for the estimated impact of the AE on the patient's LOS was nearly perfect for the DSSG cases (ICC $=0.80$ and 0.86, respectively; Table 4) and fair for the STSG cases (ICC $=0.39$ and 0.38 , respectively; Table 5).

\section{Discussion}

The results of this study provide a clinically driven definition of what constitutes an AE in spinal surgery and demonstrate substantial inter- and intraobserver reliability for categorizing AE severity based on its physical impact. Furthermore, this degree of agreement was achieved with minimal education or training on the use of SAVES-V2, with international and multicenter representation.

The inconsistency of AE reporting in the surgical literature reflects the complexity and challenges of this important issue and is currently a focus of many surgical societies and institutions. . $^{10,15,22,23,30,31,33}$ In keeping with increasing public and professional focus on medical errors, the reporting of AEs from spine surgery has significantly increased in the last several years as a primary focus of research. ${ }^{10,19,31,34}$ However, the current spine AE literature highlights the overall systemic inconsistencies associated with defining, reporting, and categorizing AEs., ${ }^{4,6,21}$ For example, in one of the largest reports on morbidity and mortality in the surgical treatment of adults with degenerative lumbar stenosis (LS) from the Scoliosis Research Society (SRS) database, Fu et al. ${ }^{10}$ documented an overall complication rate of $7 \%$. However, as noted by the authors, the accuracy of the data collection is not assured and "lesser" complications may not have been recorded. Comparatively, AE data from the Spine Outcomes Research Trial (SPORT) on LS and degenerative spondylolisthesis (DS) revealed significantly greater overall complication rates (11\% and 12\% intraoperative AEs for LS and DS, respectively, and 7\% postoperative AEs for both groups). For the broader spine surgery population, Lee et al ${ }^{19}$ reported a complication rate of $42 \%$ (679 of 1591 patients) using a prospective collection system and a broad definition of AE that included near misses. This rate is in stark contrast to the overall complication rate of $7.6 \%$ reported by Schoenfeld et al. for immediate postoperative complications following spine surgery in 3475 patients registered

TABLE 4. SAVES-V2 inter- and intraobserver agreement in the DSSG cases

\begin{tabular}{|c|c|c|c|}
\hline Parameter & Interobserver Agreement (95\% Cl) & Intraobserver Agreement (95\% Cl) & Type of Analysis \\
\hline No. in group & 17 & 8 & \\
\hline Presence of an $\mathrm{AE}$ & $99 \%$ & $100 \%$ & $\%$ agreement \\
\hline AE severity ${ }^{*}$ & $0.75(0.41-0.99)$ & $0.70(0.17-0.83)$ & $\mathrm{ICC}$ \\
\hline No. of AEs & $0.71(0.53-0.88)$ & $0.49(0.15-0.80)$ & ICC \\
\hline Specific type of AE & $0.38(0.11-0.89)$ & $0.70(0.49-0.90)$ & Cohen's kappa \\
\hline Impact of AE on LOS & $0.80(0.66-0.93)$ & $0.86(0.60-0.96)$ & ICC \\
\hline
\end{tabular}


TABLE 5. SAVES-V2 inter- and intraobserver agreement in the STSG cases

\begin{tabular}{|c|c|c|c|}
\hline Parameter & Interobserver Agreement (95\% Cl) & Intraobserver Agreement (95\% Cl) & Type of Analysis \\
\hline No. in group & 34 & 28 & \\
\hline Presence of an $\mathrm{AE}$ & $97 \%$ & $97 \%$ & $\%$ agreement \\
\hline AE severity* & $0.75(0.73-0.76)$ & $0.71(0.56-0.80)$ & ICC \\
\hline No. of AEs & $0.70(0.62-0.76)$ & $0.56(0.16-0.85)$ & ICC \\
\hline Specific type of AE & $0.80(0.79-0.82)$ & $0.65(0.44-0.85)$ & Cohen's kappa \\
\hline Impact of AE on LOS & $0.39(0.21-0.53)$ & $0.38(0.28-0.81)$ & ICC \\
\hline
\end{tabular}

in the National Surgical Quality Improvement Program..$^{32}$ Recent literature reviews of spine surgery complications have revealed significant variability, with overall complication rates ranging from $<5 \%$ to $70 \% .^{6,21,38}$ The majority of this heterogeneity is generated by 2 factors that significantly affect the frequency of reported complications and can be interrelated: 1) the definition used to trigger a positive $\mathrm{AE}$ or occurrence and 2) the method of data capture (i.e., prospective vs retrospective). This wide range of reported $\mathrm{AE}$ rates highlights the need to adopt a practical definition of and method for categorizing AEs in spine surgery. In the absence of reliable definitions for complication, adverse occurrence, or $\mathrm{AE}$, the reader must be mindful of the working definition used in any given report before making direct comparisons. Dekutoski et al. stated, "The definitions for complications in the spine literature and federal agencies are inconsistent and at times conflicting." ${ }^{6}$ Definitions such as "undesirable developments"13 or "unexpected or undesirable events" 25 are obviously open to significant subjective biases and are at least in part responsible for the existing variability. We (STSG and DSSG) adapted the definition used by Rampersaud et al., ${ }^{26}$ which states that an $\mathrm{AE}$ is any event due to medical or surgical management, but not resulting from underlying disease process or injury, that leads to patient harm or requires additional monitoring or treatment. Although no perfect definition exists, the current definition provides a greater degree of objectivity by specifically identifying patient harm, additional monitoring, or treatment. Although it eliminates the more subjective aspects of near misses and psychological events by requiring that physical harm has occurred, "harm" still leaves a degree of subjectivity. Accordingly, although we achieved a high degree of agreement (97\%-100\%; Tables 4 and 5), 100\% agreement on the presence of an AE was not achieved in our study. In contrast, Lebude et al. ${ }^{18}$ performed a survey of 229 spine surgeons focused on defining complications. The authors did not provide the participants with a specific working definition of what constitutes a complication (i.e., an AE) and reported that more than $75 \%$ of surgeons agreed on the presence or absence of a complication in 10 of 11 case scenarios.

In addition to inconsistent definitions of what constitutes an $\mathrm{AE}$, significant variability also exists when defining the relative severity of an AE. $5,8,18,20,26$ The majority of surgeons pragmatically categorize AEs into minor and major events. The reliability of this binary severity categorization was assessed in the survey by Lebude et al. ${ }^{18}$ In 7 (64\%) of 11 scenarios, there was consensus among surgeons, with over
$70 \%$ of respondents agreeing with one answer. The authors reported fair agreement (Cohen's kappa $=0.37$ ) across all the scenarios. While a binary approach is certainly the simplest method of severity grading, the results from Lebude et al. highlight concerns regarding the validity of using aggregate data across individuals or institutions. The binary approach, unfortunately, does not provide the more detailed clinical picture surrounding an AE. For example, a dural tear that requires a simple stitch or no treatment would be considered minor; however, the dural tear with a persistent leak that requires a lumbar drain (unless that is considered a reoperation), prolonged bed rest, and an additional 10 days of hospital stay or a readmission would still be categorized as minor based on the definition by Lebude et al. ${ }^{18}$ In the SAVES system, a dural tear not associated with a permanent neurological deficit could be graded from 1 to 4 . In another example, a patient with transient neurological deterioration who is showing signs of recovery and will probably completely recover in 6-12 months may still be graded as having a minor $\mathrm{AE}$, whereas the $\mathrm{AE}$ would be graded as 3 or 4 using SAVES-V2. Furthermore, certain processes or AEs that require formal institutional reporting, such as wrong-level surgery, and are recognized and corrected at the index procedure would not be specifically flagged by such an approach. From a research, quality improvement, and health systems perspective, a balance between greater degree of detail and ease of use is required to enable more meaningful analysis of aggregate data., 50 Comparatively, we feel the substantial inter- and intraobserver agreement for $\mathrm{AE}$ severity in the current study (Tables 4 and 5) supports the need for consistent severity definitions across users.

As regards ease of use, the only other spine-specific system for comparison is the one reported by Mirza et al. ${ }^{20}$ In that system, the authors used the terms "adverse occurrence" (near misses) and "AE" (patient harm) to describe the safety of spinal operations. Although spine specific, the framework used by the authors included components of patient characteristics, disease attributes (e.g., severity), and treatment factors (e.g., surgical invasiveness) that are applicable to other areas of surgery. The authors demonstrated that rigorous daily assessments by observers identified $92.6 \%$ of the recorded adverse occurrences, compared with only $38.5 \%$ identified by voluntary reports from the care team. Using an 11-category severity scale, Mirza et al. showed substantial interobserver reliability $(\mathrm{ICC}=0.74)$ for the classification of adverse occurrence severity for spine patients, which compares favorably to the reliability demonstrated in our study's 6-category sys- 
tem. However, the 2 studies differ in the focus and complexity of the assessment. Comparatively, in the study by Mirza and colleagues, 4 experienced clinicians (3 staff spine surgeons and 1 staff anesthesiologist) from the same center assessed multiple factors including potential and actual harm occurrences and causation. The reviewers participated in 3 training sessions and were then provided with relevant information for each occurrence before categorizing it. In addition, the reviewers used a more comprehensive data dictionary (developed by the clinicians in a consensus-based manner) for each specific adverse occurrence or AE (available as an appendix in the publication). ${ }^{20}$ Nonetheless, only fair agreement (Cohen's kappa = 0.35 ) in the etiology of adverse occurrences was achieved between the reviewers. Although Mirza and colleagues used a more scientifically rigorous process, these authors did acknowledge that it would be very difficult to routinely implement such a system into a busy, high-volume setting. In the current study, similar reliability was demonstrated with minimal training. Thus, SAVES-V2 may provide a simpler system that enables more practical point-of-care implementation across different institutions.

The broad multicenter representation provided by the STSG and DSSG participants has strengthened the generalizability of this study. Furthermore, the similar overall reliability in severity grading between degenerative and traumatic spinal conditions suggests SAVES-V2 has strong potential for use within spine subspecialties. However, this advantage also translates into an equally important limitation since our study used case scenarios. Consequently, unlike the findings by Mirza et al., ${ }^{20}$ our results do not necessarily represent reliability in clinical use. Previous work by the first authors suggests that the reliability of SAVES (version 1) may, in fact, be better at the point of care at which all relevant information for a given $\mathrm{AE}$ would be more deeply understood by the grader. Using the 4-grade SAVES system, Rampersaud et al. ${ }^{26}$ demonstrated simple implementation of the SAVES form by the surgical team (surgeon, fellow, resident, nurse practitioner), with substantial reliability among the different members and the identification of $30 \%$ more surgical AEs and 10\% more medical AEs compared with the current standard of chart abstraction. More recently, Street et al. ${ }^{34}$ noted a dramatic increase in the prevalence of AEs after introducing the SAVES-V2 for weekly multidisciplinary patient rounds in a high-volume quaternary care spine center. The authors demonstrated substantial agreement in the severity grading among 3 surgeons and among a surgeon, resident, and nurse for a given AE. The authors also reported a significant increase in the incidence of AEs, from $23 \%$ with retrospective data capture to $87 \%$ with the prospective use of the SAVES-V2. The majority of AEs were postoperative, with the most common being electrolyte imbalance (incidence $=46 \%$ ) and medication-related side effects (incidence $=41 \%$ ). The authors noted that in an effort to further define harm from an AE, they captured all possible abnormalities to more rigorously assess the clinical impact. In the absence of categorizing electrolyte and medication AEs, the overall AE incidence reported by Street et al. ${ }^{34}$ is similar to that of Rampersaud et al. ${ }^{26}$ In a subsequent publication, Street et al. ${ }^{35}$ also demonstrated that the SAVES-
V2 identified twice as many AEs compared with administrative data abstraction using ICD-10 coding.

This study has other limitations that require discussion. The intraobserver reliability aspect was less than ideal in 2 respects. In the DSSG, just under half of the participants were able to complete the second round. We acknowledge that this is less than ideal and a limitation. This weakness can be addressed in future studies confirming the reliability of the findings. A much better completion rate $(82 \%)$ was achieved in the larger STSG. With the exception of the estimated impact of an AE on LOS, the intraobserver reliability results were very similar between the 2 groups, suggesting that the results for the DSSG are still valid. Despite the fact that one of the strengths of this system is the need for minimal education, there was only fair agreement in the DSSG group for the specific type of AE. As noted, the reliability would have increased if incorrect categorization had been accounted for or if a data dictionary or more specific education on each AE listed on the form had been provided. Moreover, providing an "other" category often becomes a more efficient, yet erroneous, default response for participants. This is an issue that typically improves over time as a user becomes more experienced with a grading system. The SAVES-V2 question on estimating the impact of an AE on LOS is meant to be used in patients in whom real-time, point-of-care data could more realistically estimate the discharge day if the $\mathrm{AE}(\mathrm{s})$ had not occurred. This unique portion of SAVES-V2 allows a surrogate estimate to be made for the healthcare utilization impact of the AE, in cases in which detailed data on other factors that impact LOS (e.g., regional system/country variations) are not readily available. In the current study, the STSG demonstrated only fair inter- and intraobserver agreement for trauma cases in this category, whereas the DSSG reported near perfect agreement for degenerative cases. This finding is most likely attributable to trauma patients who present with a wide spectrum of spine- and nonspine-related injuries and will have a much greater variation in LOS, compared with the typically routine and common scenarios presented by patients in the degenerative cases. Further research is needed to identify methods for estimating or refining the SAVES-V2 instrument to determine the effect of AEs on LOS in trauma patients.

\section{Conclusions}

SAVES-V2 may represent a simple tool that enables improved and consistent capture of spinal surgery AE data across institutions. The results of this study demonstrate substantial inter- and intraobserver reliability in the use of SAVES-V2 for grading the severity of AEs commonly associated with spine surgery. Furthermore, minimal education and training on the system was required among a broad cross-section of spine surgeons.

\section{Acknowledgments}

We thank all members of the STSG and DSSG for their participation in this study. We also acknowledge the study group co-chairs (STSG: Drs. Marcel Dvorak, Michael Fehlings, and Alex Vaccarro; DSSG: Drs. Charles Branch, David Polly, and Vince 
Traynelis) for their support and approval of this study. Analysis of the data by $\mathrm{PhDx}$ was supported by Medtronic as part of the overall support for the operation of the STSG and DSSG.

\section{References}

1. Berlinger N, Wu AW: Subtracting insult from injury: addressing cultural expectations in the disclosure of medical error. $\mathbf{J}$ Med Ethics 31:106-108, 2005

2. Brennan TA, Leape LL, Laird NM, Hebert L, Localio AR, Lawthers AG, et al: Incidence of adverse events and negligence in hospitalized patients: results of the Harvard Medical Practice Study I. 1991. Qual Saf Health Care 13:145-152, 2004

3. Bruce J, Russell EM, Mollison J, Krukowski ZH: The measurement and monitoring of surgical adverse events. Health Technol Assess 5:1-194, 2001

4. Campbell PG, Malone J, Yadla S, Chitale R, Nasser R, Maltenfort MG, et al: Comparison of ICD-9-based, retrospective, and prospective assessments of perioperative complications: assessment of accuracy in reporting. J Neurosurg Spine 14:16-22, 2011

5. Chang A, Schyve PM, Croteau RJ, O'Leary DS, Loeb JM: The JCAHO patient safety event taxonomy: a standardized terminology and classification schema for near misses and adverse events. Int J Qual Health Care 17:95-105, 2005

6. Dekutoski MB, Norvell DC, Dettori JR, Fehlings MG, Chapman JR: Surgeon perceptions and reported complications in spine surgery. Spine (Phila Pa 1976) 35 (9 Suppl):S9-S21, 2010

7. Deyo RA, Mirza SK, Martin BI, Kreuter W, Goodman DC, Jarvik JG: Trends, major medical complications, and charges associated with surgery for lumbar spinal stenosis in older adults. JAMA 303:1259-1265, 2010

8. Dindo D, Demartines N, Clavien PA: Classification of surgical complications: a new proposal with evaluation in a cohort of 6336 patients and results of a survey. Ann Surg 240:205213, 2004

9. Elder NC, Dovey SM: Classification of medical errors and preventable adverse events in primary care: a synthesis of the literature. J Fam Pract 51:927-932, 2002

10. Fu KMG, Smith JS, Polly DW, Ames CP, Berven SH, Perra $\mathrm{JH}$, et al: Morbidity and mortality associated with spinal surgery in children: a review of the Scoliosis Research Society morbidity and mortality database. J Neurosurg Pediatr 7:37-41, 2011

11. Hofer TP, Kerr EA, Hayward RA: What is an error? Eff Clin Pract 3:261-269, 2000

12. Institute of Medicine: Patient Safety: Achieving a New Standard of Care. Washington, DC: National Academy Press, 2003

13. Institute of Medicine: To Err Is Human: Building a Safer Health System. Washington, DC: National Academy Press, 1999

14. Kenneth W, Kizer K, Robyn Y, Nishimi R, Power E: Standardizing a Patient Safety Taxonomy: A Consensus Report. Washington, DC: National Quality Forum, 2006

15. Krizek TJ: Surgical error: ethical issues of adverse events. Arch Surg 135:1359-1366, 2000

16. Landis JR, Koch GG: The measurement of observer agreement for categorical data. Biometrics 33:159-174, 1977

17. Leape LL, Brennan TA, Laird N, Lawthers AG, Localio AR, Barnes BA, et al: The nature of adverse events in hospitalized patients. Results of the Harvard Medical Practice Study II. N Engl J Med 324:377-384, 1991

18. Lebude B, Yadla S, Albert T, Anderson DG, Harrop JS, Hilibrand A, et al: Defining "complications" in spine surgery: neurosurgery and orthopedic spine surgeons' survey. J Spinal Disord Tech 23:493-500, 2010
19. Lee MJ, Konodi MA, Cizik AM, Bransford RJ, Bellabarba C, Chapman JR: Risk factors for medical complication after spine surgery: a multivariate analysis of 1,591 patients. Spine J 12:197-206, 2012

20. Mirza SK, Deyo RA, Heagerty PJ, Turner JA, Lee LA, Goodkin R: Towards standardized measurement of adverse events in spine surgery: conceptual model and pilot evaluation. BMC Musculoskelet Disord 7:53, 2006

21. Nasser R, Yadla S, Maltenfort MG, Harrop JS, Anderson DG, Vaccaro AR, et al: Complications in spine surgery. J Neurosurg Spine 13:144-157, 2010

22. Nohara Y, Taneichi H, Ueyama K, Kawahara N, Shiba K, Tokuhashi Y, et al: Nationwide survey on complications of spine surgery in Japan. J Orthop Sci 9:424-433, 2004

23. Ohrn A, Olai A, Rutberg H, Nilsen P, Tropp H: Adverse events in spine surgery in Sweden: a comparison of patient claims data and national quality register (Swespine) data. Acta Orthop 82:727-731, 2011

24. Pierluissi E, Fischer MA, Campbell AR, Landefeld CS: Discussion of medical errors in morbidity and mortality conferences. JAMA 290:2838-2842, 2003

25. Rampersaud YR, Moro ERP, Neary MA, White K, Lewis SJ, Massicotte EM, et al: Intraoperative adverse events and related postoperative complications in spine surgery: implications for enhancing patient safety founded on evidence-based protocols. Spine (Phila Pa 1976) 31:1503-1510, 2006

26. Rampersaud YR, Neary MA, White K: Spine adverse events severity system: content validation and interobserver reliability assessment. Spine (Phila Pa 1976) 35:790-795, 2010

27. Reinertsen JL: Let's talk about error. West J Med 172:356357,2000

28. Ricci M, Goldman AP, de Leval MR, Cohen GA, Devaney F, Carthey J: Pitfalls of adverse event reporting in paediatric cardiac intensive care. Arch Dis Child 89:856-859, 2004

29. Runciman WB, Helps SC, Sexton EJ, Malpass A: A classification for incidents and accidents in the health-care system. J Qual Clin Pract 18:199-211, 1998

30. Runciman WB, Webb RK, Helps SC, Thomas EJ, Sexton EJ, Studdert DM, et al: A comparison of iatrogenic injury studies in Australia and the USA. II: Reviewer behaviour and quality of care. Int J Qual Health Care 12:379-388, 2000

31. Sansur CA, Smith JS, Coe JD, Glassman SD, Berven SH, Polly DW Jr, et al: Scoliosis research society morbidity and mortality of adult scoliosis surgery. Spine (Phila Pa 1976) 36:E593-E597, 2011

32. Schoenfeld AJ, Ochoa LM, Bader JO, Belmont PJ Jr: Risk factors for immediate postoperative complications and mortality following spine surgery: a study of 3475 patients from the National Surgical Quality Improvement Program. J Bone Joint Surg Am 93:1577-1582, 2011

33. Sobottke R, Aghayev E, Röder C, Eysel P, Delank SK, Zweig T: Predictors of surgical, general and follow-up complications in lumbar spinal stenosis relative to patient age as emerged from the Spine Tango Registry. Eur Spine J 21:411-417, 2012

34. Street JT, Lenehan BJ, DiPaola CP, Boyd MD, Kwon BK, Paquette SJ, et al: Morbidity and mortality of major adult spinal surgery. A prospective cohort analysis of 942 consecutive patients. Spine J 12:22-34, 2012

35. Street JT, Thorogood NP, Cheung A, Noonan VK, Chen J, Fisher CG, et al: Use of the Spine Adverse Events Severity System (SAVES) in patients with traumatic spinal cord injury. A comparison with institutional ICD-10 coding for the identification of acute care adverse events. Spinal Cord 51:472-476, 2013

36. Thomas EJ, Studdert DM, Burstin HR, Orav EJ, Zeena T, Williams EJ, et al: Incidence and types of adverse events and negligent care in Utah and Colorado. Med Care 38:261-271, 2000

37. Vincent C, Neale G, Woloshynowych M: Adverse events in 
British hospitals: preliminary retrospective record review. BMJ 322:517-519, 2001

38. Weiss HR, Goodall D: Rate of complications in scoliosis surgery-a systematic review of the PubMed literature. Scoliosis 3:9, 2008

39. Whitmore RG, Stephen J, Stein SC, Campbell PG, Yadla S, Harrop JS, et al: Patient comorbidities and complications after spinal surgery: a societal-based cost analysis. Spine (Phila Pa 1976) 37:1065-1071, 2012

40. Wilson RM, Runciman WB, Gibberd RW, Harrison BT, Newby L, Hamilton JD: The Quality in Australian Health Care Study. Med J Aust 163:458-471, 1995

41. Wilson-MacDonald J, Fairbank J, Frost H, Yu LM, Barker K, Collins R, et al: The MRC spine stabilization trial: surgical methods, outcomes, costs, and complications of surgical stabilization. Spine (Phila Pa 1976) 33:2334-2340, 2008

42. Wu AW: Medical error: the second victim. The doctor who makes the mistake needs help too. BMJ 320:726-727, 2000

\section{Disclosures}

Dr. Fisher is a consultant with Medtronic and Nuvasive. Dr. Rampersaud is a consultant with Medtronic. Dr. Dimar is a consultant with Medtronic and Depuy and holds patents with Medtronic. All authors received travel and accommodation reimbursement from Medtronic to attend the respective study group meetings where the study was performed.

\section{Author Contributions}

Conception and design: all authors. Acquisition of data: Rampersaud. Analysis and interpretation of data: all authors. Drafting the article: Rampersaud. Critically revising the article: all authors. Reviewed submitted version of manuscript: all authors. Approved the final version of the manuscript on behalf of all authors:

Rampersaud. Administrative/technical/material support: Rampersaud. Study supervision: Rampersaud.

\section{Supplemental Information}

\section{Online-Only Content}

Supplemental material is available with the online version of the article.

Appendices 1 and 2. http://thejns.org/doi/suppl/10.3171/2016.1. SPINE14808

\section{Previous Presentations}

A portion of these data was presented at the 25th Annual North American Spine Society meeting held in Orlando, Florida, on October 5-9, 2010.

\section{Correspondence}

Y. Raja Rampersaud, Toronto Western Hospital, Division of Orthopaedic Surgery, 1 East Wing, Rm. 449, 399 Bathurst St., Toronto, ON M5T 2S8, Canada. email: raja.rampersaud@uhn.ca. 